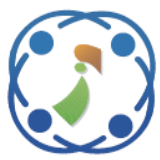

\title{
Optimal Sizing of Supercapacitor Energy Storage Based on Firefly Algorithm for Enhancing Critical Clearing Time
}

\author{
Talitha Puspita Sari ${ }^{1}$ \\ Maya Prananda Sari ${ }^{1}$ \\ Ardyono Priyadi ${ }^{1}$ \\ Vita Lystianingrum ${ }^{1}$ \\ Gabriela Evania Sulistyo ${ }^{2}$ \\ Mauridhi Hery Purnomo $1,2,3 *$ \\ ${ }^{I}$ Department of Electrical Engineering, Institut Teknologi Sepuluh Nopember, Indonesia \\ ${ }^{2}$ Department of Computer Engineering, Institut Teknologi Sepuluh Nopember, Indonesia \\ ${ }^{3}$ University Center of Excellence on Artificial Intelligence for Healthcare and Society (UCE AIHeS), Indonesia \\ * Corresponding author's Email: hery@ee.its.ac.id
}

\begin{abstract}
In the present day, the electrical power demand is increasing and expected to continue growing. The renewable energy sources as the power supply are also increasing but not much as needed. As a result, the power systems operate close to their maximum stability limit. This paper proposed to extend the value of Critical Clearing Time (CCT) to enhance the stability system, especially the transient stability. A Supercapacitor Energy Storage (SCES) is installed at one of the generator bus; however, the sizing of SCES must be optimized due to the economics and power balance constraint. In this paper, the Firefly Algorithm (FA) is used to obtain the optimal sizing of SCES with the objective function is the highest value of CCT. Lagrange interpolation is used to validate the effectiveness of FA, such as computation time and accuracy. According to the simulation result obtained, the proposed method using FA has a faster calculation time than Lagrange interpolation. Moreover, the proposed method is validated on a modified IEEE 9 bus with various cases. By using FA, the best increase of CCT is obtained when the optimal size of SCES is 0.120 p.u. The overall CCT increase is 0.15766 s or around $54.61 \%$.
\end{abstract}

Keywords: Critical clearing time, Firefly algorithm, Supercapacitor energy storage, Transient stability.

\section{Introduction}

In recent years, a promising and critical intelligent generation known as the smart grid becomes the main issue in the power system. The incremental supply for electrical energy is needed due to the escalation of the industry and modern technologies. The power systems are forced to operate near their stability limits due to very complex and nonlinear conditions. Many countries use the Renewable Energy Source (RES) to increase the supply energy with less carbon [1]. However, the interconnection system between RES and the main grid must be resilient and efficient. The next challenge is the instabilities and the security of the power system in synchronizing RES and the main grid [2-4]. Moreover, the power system's continuity and reliability when any disturbance happened in the system must be maintained. The protection system must secure the system and ensure the stability of the power system. Thus, the monitoring study of transient disturbance is needed to know the effects on system protection $[5,6]$.

Several types of research related to power system stability, such as the fastest identification, detection, and managing the power system, are needed to improve the online monitoring assessment in the power system. Machine learning approaches are used to learn the stability and the security of the power system [2]. In enhancing the power quality, swarm intelligence, such as the firefly algorithm, particle swarm, ant bee colony, and others, are used to enhance the power quality [7].

Rani and Ramakrishnan use modified particle swarm optimization, such as the binary particle swarm optimization and unified particle swarm optimization. The radial power distribution system is chosen to be the test system to get the optimal 
network reconfiguration with the addition of a distributed generator $[8,9]$. The enhance water cycle algorithm and grey wolf's algorithm are proposed by $[10,11]$ for power system distribution. [10, 11] focuses on enhancing the voltage stability index and minimizing the system power losses. However, some papers mention that the firefly algorithm is better than genetic algorithms, particle swarm optimization, and artificial bee colonies because they can be implemented in parallel. Moreover, the firefly algorithm is more efficient in finding global optima with a higher success rate $[12,13]$.

The firefly algorithm was proposed by Balachennaiah to optimize the real power loss and voltage stability index for a large transmission network. Balachennaiah validated that the firefly algorithm has a better result than a real coded genetic algorithm and interior-point successive linear programming technique [14]. Jagatheesan proposed the design of a proportional-integral-derivative controller for an automatic generation control for a multi-area power system. Firefly algorithm shows a better result compared with other optimization algorithms, such as genetic algorithm and particle swarm optimization technique [15]. Moreover, a chaotic firefly algorithm and adaptive modified firefly algorithm were used to optimize the overcurrent relay coordination [16-18]. To enhance the power system stabilizer controller, a firefly algorithm was proposed in each machine for tuning the controller [19, 20]. A self-adaptive firefly algorithm to obtain the optimal placement of flexible alternating current transmission systems is proposed by [21]. Moreover, the firefly algorithm was proposed by [22] in optimizing the controller of generation control in a system with a unified power flow controller and Superconducting Magnetic Energy Storage (SMES).

SMES and Supercapacitor Energy Storage (SCES) are examples of the energy storage system that can improve the power system stability, especially transient stability. It acts as an additional damping that reduces the oscillation when a large disturbance happens. Liu proposed the "plug and play" rules to optimize the SMES operation in the smart grid [23]. The reinforcement learning method proposed by [24] for SMES device to increase the transient stability. On the other hand, SCES was proposed to extend the critical clearing time value when a large disturbance occurs in the system. As a result, the system has additional time to avoid the worst condition [25, 26]. [27] shows that the differential evolution algorithm can be used to optimize the generator's critical clearing time. However, it only validated in a single machine to an infinite bus and calculated the critical clearing time using equal area criterion. However, the latest research shows that SCES has more advantages than SMES, such as higher power density, has fast charging and discharging, high reliability, durability, maintenance-free, and environment save [28, 29].

In this paper, it is motivated to perform the SCES sizing optimization with the objective of enhancing the transient stability using FA. FA is chosen because it has faster calculation than others standard interpolation calculation. In this paper, Lagrange interpolation is used for the comparison with the proposed method. The objective function of both method is obtaining the highest CCT value. In addition, different cases for the fault location are presented to verify and highlight the effectiveness of the proposed method. A modified IEEE 3-machines 9-bus system was chosen to carry out the different cases.

Accordingly, the remainder of the paper is organized as follows. Section 2 present the notation list of the variables that used in this paper. A brief description of transient stability assessment is articulated in Section 3. Section 4 describes the proposed method in finding the sizing of the SCES. The result and discussion of the proposed method is demonstrated in Section 5. Finally, Section 6 concludes the research works and the future works.

\section{Nomenclature and abbreviations}

The following notations will be used in this paper. $M_{i} \quad$ inertia constant of generator $i$

$M_{T} \quad$ total of inertia constant

$\omega_{0} \quad$ initial synchronous speed

$\omega_{i} \quad$ synchronous speed of generator $i$

$\widetilde{\omega}_{i} \quad \omega_{i}-\omega_{0}$

$P_{m i} \quad$ mechanical power of generator $i$

$P_{e i} \quad$ electrical power of generator $i$

$P_{S C E S} \quad$ SCES power

$P_{S C E S, \min }$ minimum value of SCES power

$P_{S C E S, \max }$ maximum value of SCES power

$P_{C O A} \quad$ center of angle/inertia power

$D \quad$ damping

$\delta_{0} \quad$ initial rotor position

$\delta_{i} \quad$ rotor position of generator $i$

$\theta_{i} \quad \delta_{i}-\delta_{0}$

$Y_{i j} \quad$ admittance matrix

$E_{i j} \quad$ internal voltage of the generator

I light intensity variation of firefly

$I_{0} \quad$ original light intensity of firefly

$\alpha \quad$ randomization parameter determined based on the complexity of the problem, which is from the interval $[0,1]$ 


$\begin{array}{ll}\beta & \text { the attractiveness of firefly } \\ \beta_{0} & \text { initial attractiveness of firefly at } r=0 \\ \gamma & \begin{array}{l}\text { absorption coefficient which controls } \\ \text { the decrease of the light intensity }\end{array} \\ r_{i, j} & \begin{array}{l}\text { distance between two fireflies } i \text { and } j \text { at } \\ x_{i} \text { and } x_{j}\end{array} \\ x_{i, k} & \begin{array}{l}\text { th component of the spatial coordinate } \\ x_{i} \text { of the } i \text { th firefly }\end{array} \\ d & \begin{array}{l}\text { dimension number of the problem } \\ \varepsilon_{i}\end{array} \\ & \begin{array}{l}\text { vector of random numbers chosen from } \\ \text { uniform distribution or Gaussian }\end{array} \\ & \text { distribution }\end{array}$

$\begin{array}{lll}\text { Abbreviation } \\ R E S & \text { renewable energy source } \\ \text { SCES } & \text { supercapacitor energy storage } & \\ \text { SMES } & \text { superconducting magnetic energy } \\ & \begin{array}{l}\text { storage } \\ \text { critical clearing time }\end{array} \\ \text { FCT } & \text { firefly algorithm } \\ \text { UEP } & \text { unstable equilibrium point }\end{array}$

\section{Power system stability assessment}

Transient stability known as the large-disturbance rotor angle stability, is the ability of the synchronous machines which are interconnected to maintain its synchronism after a large disturbance happens [30]. The equilibrium of the electromagnetic torque and mechanical torque is essential in determining the stability of the system. The angular swing is increasing due to the instability and lead to losing synchronism of the generators. Transient instability is the main cause of the power instability problem, including islanding and blackout in some countries.

The transient stability index is measured through Critical Clearing Time (CCT), which is defined as the fault clearing time when the system becomes stable after the fault clearance. If the fault clearing time exceeds the CCT, the system becomes unstable; otherwise, it is stable. There are two main methods in calculating CCT, such as direct method and indirect method. An indirect method, known as the conventional numerical method or time-domain simulation method, is believed to have good accuracy. The drawback of the indirect method is providing a range of approximated CCT, but the specific value can be found by adjusting the fault duration time through trial and error $[31,32]$. The direct method uses various numerical integration to obtain the CCT value, such as equal area criterion, energy-function method, critical trajectory method, and others. Equal area criterion and energy-function method use energy balance to obtain the CCT value [33].
In this paper, the CCT is obtained using the critical trajectory method. The critical trajectory method used four trajectories to imply the method: the on-fault trajectory, the stable trajectory, the unstable trajectory, and the critical trajectory. The critical trajectory is the trajectory, which is located between stable and unstable trajectory $[34,35]$. The endpoint condition of the critical trajectory is the Unstable Equilibrium Point (UEP), where each machine has its UEP value.

Some researchers proposed various alternatives in enhancing the power system stability, especially transient stability. One of the alternatives methods is by extending the CCT. By extending the CCT value, the protection system has more time to respond when a disturbance happens. It becomes an alternative when the protection system has mal-tripping due to false sensing or error in the protection system. With the increase of the CCT, the delay can be tolerated for a fraction of a second. As a result, the system operators able to evaluate and organize the corrective action to preserve the power system stability to avoid the failure and blackout [36].

Supercapacitor Energy Storage (SCES) has a high response time and ramp rate capability, which is in accordance with the needs of transient stability. The SCES works to damp the oscillation in transient time because the governor system cannot absorb the frequency fluctuation due to the governor is a slow response device. Recent researches show that SCES has more advantages than other energy storage devices. SCES has an extremely high power density and fast charging/discharging rather than other energy storage devices. SCES is adequate for the application in the remote sites because it has a longer lifetime and maintenance-free. SCES is also known as environmentally friendly because it is easily recycled. Moreover, the efficiency of SCES is around $75-95 \%[28,29]$.

Firefly Algorithm (FA) is one of the natureinspired algorithms, a meta-heuristic optimization algorithm that depicts the characteristics of fireflies developed by Xin She Yang [37]. There are three idealized behavior rules in FA: The first rule is that all the fireflies are unisexual, and sex has no effect on their movement. It moves toward the brightness ones. The second rule is that the degree of attractiveness is proportional with their brightness. The one with less bright will move towards to the brighter one. If there the fireflies have the same brightness, it will move randomly. The final rule is the value of the objective function to be optimized becomes the brightness firefly.

The advantage of the FA is the ability that divides the initial population into a subgroup. FA has been 
proven to be efficient at solving the optimization problems than other meta-heuristic algorithms related to nonlinear optimization problems, which is suitable for the transient stability assessment. Moreover, some researches proved that FA gives an excellent result more than other algorithms. In this paper, FA is used as the option to do the online monitoring in stability assessment. Using FA, the calculation is faster than the previous method, such as calculating using Lagrange interpolation method and manually.

\section{Problem formulation}

\subsection{Power system modelling}

In this paper, a modified IEEE 3-machine 9-bus used to validate the proposed method. The modified system consists of one main grid and two small renewable energies, as depicted in Fig. 1. The system is assumed to have a double circuit line transmission. To enhance the transient stability, the SCES is installed at bus generator 2. A three-phase fault is subjected to the system to check the CCT value of the system.

There are several points of fault to test the proposed method, which explained as follows:

- Fault point A located between bus 2 and 7, but it near to bus 2

- Fault point B located between bus 3 and 9, but it near to bus 3

- Fault point $\mathrm{C}$ located between bus 4 and 5, but it near to bus 4

- Fault point D located between bus 4 and 6 , but it near to bus 4

- Fault point E located between bus 5 and 7, but it near to bus 7

- Fault point $F$ located between bus 7 and 8 , but it near to bus 7

- Fault point G located between bus 6 and 9, but it near to bus 9

- Fault point $\mathrm{H}$ located between bus 8 and 9, but it near to bus 9

- Fault point I located between bus 8 and 9, but it near to bus 8

The swing equation model of the power system is described as follows:

$$
\begin{gathered}
M_{i} \dot{\widetilde{\omega}}_{i}=P_{m i}-P_{e i}(\theta)-\frac{M_{i}}{M_{T}} P_{C O A}-D_{i}(\widetilde{\omega}) \\
-P_{S C E S} \\
\dot{\theta}_{i}=\widetilde{\omega}_{i}
\end{gathered}
$$

where:

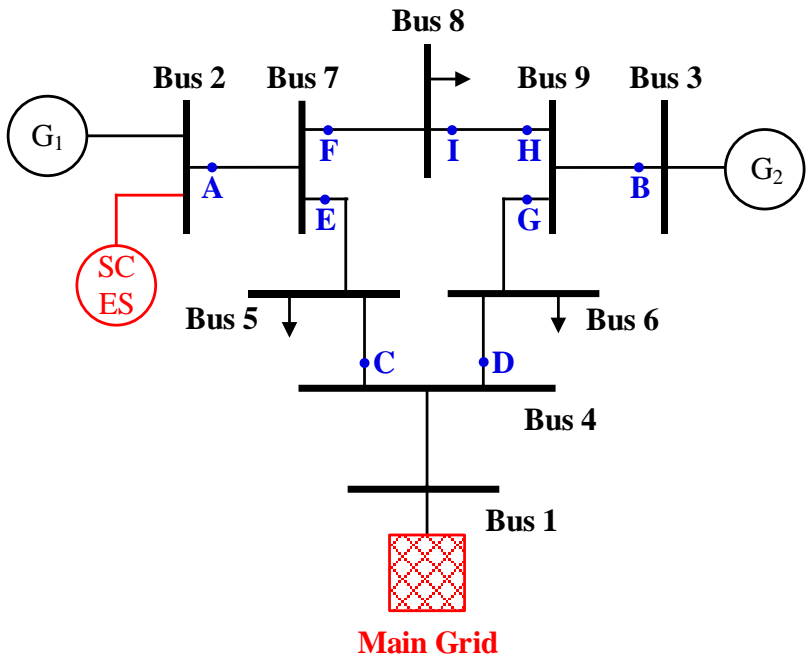

Figure. 1 Single line diagram of modified IEEE 3machine 9-bus system

$$
\begin{gathered}
M_{T}=\sum_{i=1}^{n}\left(M_{T}\right) \\
P_{e i}(\theta)=\sum_{j=1}^{n}\left(Y_{i j} E_{i} E_{j} \sin \left(\theta_{i}-\theta_{j}+\alpha_{i j}\right)\right) \\
\theta_{i}=\delta_{i}-\delta_{0} ; \widetilde{\omega}_{i}=\omega_{i}-\omega_{0} \\
P_{C O A}=\sum_{i=1}^{n}\left(P_{m i}-P_{e i}(\delta)\right)
\end{gathered}
$$

$M$ is the inertia constant, $\omega$ is the synchronous speed, $P_{e i}$ is the electrical power, $P_{m}$ is the mechanical power, $P_{S C E S}$ is the SCES power, $D$ is the damping, and $\delta$ is the rotor position. Moreover, $Y_{i j}, E_{i j}$, and $\alpha_{i j}$ are the admittance matrix, an internal voltage of the generator, and constants, respectively.

\subsection{Modified lagrange interpolation}

Modified Lagrange interpolation is a polynomial interpolation to get the certain values at the arbitrary points. It can be used to get the value of SCES by calculating the CCT at first. The first derivative of the function is used to get the optimal value of SCES. However, the result must be validated using others method or using a ranking method. As a result, this method is time consuming compared with the metaheuristic method. Thus, this method cannot be used for stability online monitoring assessment. The pseudocode of Lagrange interpolation is shown below.

\section{Algorithm for Modified Lagrange Interpolation. \\ Start \\ $\%$ Calculating CCT using critical trajectory method}




\section{\% Sizing SCES}

Read number of data $(k)$

Read data :

For $i=1$ to $k$

Read $x_{i}$ and $y_{i}$

Next $i$

Read $x_{p}$

Initialize $\mathrm{P}=0$

For $i=1$ to $k$

$\mathrm{L}(i)=1$

For $j=1$ to $k$

$$
\text { If } i \neq j
$$

End if

$$
\mathrm{L}(i)=\mathrm{L}(i) *\left(\left(x_{p}-x_{j}\right) /\left(x_{i}-x_{j}\right)\right)
$$

Next $j$

Next $i$

$\mathrm{P}=\mathrm{P}+\mathrm{L}(i) * y_{i}$

Print $\mathrm{P}$

\section{$\%$ Defining the optimal SCES value}

If $\mathrm{CCT}_{n}>\mathrm{CCT}_{n+1}$

Then $\mathrm{CCT}_{\text {new }}=\mathrm{CCT}_{n}$

Else $\mathrm{CCT}_{\text {new }}=0$

If $\mathrm{CCT}_{\text {new }}=\mathrm{CCT}_{n}$

If $\mathrm{P}_{\mathrm{SCES} n}<\mathrm{P}_{\mathrm{SCES} n+1}$

Then $\mathrm{P}_{\mathrm{SCES} \text { new }}=\mathrm{P}_{\mathrm{SCES} n}$

Else 0

Else 0

End

\subsection{Firefly algorithm}

For the proper design of FA, the variation of light intensity, $I$, and the attractiveness, $\beta$, is needed. The light intensity varies with the distance, $r$, is given as follows:

$$
I=I_{0} \exp \left(-\gamma r^{2}\right)
$$

where $I_{0}, r$, and $\gamma$ are the original light intensity, the distance between fireflies, and the absorption coefficient, which controls the decrease of the light intensity, respectively.

The attractiveness of the firefly is determined by the brightness or the light intensity, which is correlated with the objection function of the algorithm. $\beta$ can be defined as:

$$
\beta=\beta_{0} \exp \left(-\gamma r^{m}\right), \text { with } m \geq 1,
$$

where $\beta_{0}$ is the initial attractiveness at $r=0$.
The distance between two fireflies $i$ and $j$ at $x_{i}$ and $x_{j}$, which is expressed as Euclidean distance, is given as follows:

$$
r_{i j}=\left\|x_{i}-x_{j}\right\|=\sqrt{\sum_{k=1}^{d}\left(x_{i, k}-x_{j, k}\right)^{2}}
$$

where $x_{i, k}$ is the ${ }^{k}$ th component of the spatial coordinate $x_{i}$ of the ${ }^{i}$ th firefly, and $\mathrm{d}$ is the dimension number of the problem.

In each generation, the ${ }^{i}$ th firefly is attracted to the brighter firefly $j$, called as the firefly movement is expressed as:

$$
x_{i}=x_{i}+\beta_{0} \exp \left(-\gamma r_{i j}^{2}\right)\left(x_{i}-x_{j}\right)+\alpha \varepsilon_{i}
$$

where $\alpha$ is the randomization parameter determined based on the complexity of the problem, which is from the interval $[0,1] . \varepsilon_{i}$ is and the vector of random numbers chosen from uniform distribution or Gaussian distribution. The first, second, and third terms are the current position of a firefly, the firefly movement based on the attractiveness, and the random movement of the firefly, respectively.

At the end of the generation, the fireflies are ranked based on their brightness, and the best firefly is chosen. The light intensity of the fireflies is always updated in accordance with the fitness function. As a result, the optimal solution is chosen from the best firefly with the highest brightness.

In this paper, the optimal sizing of SCES is calculated using FA to enhance the transient stability. The objective function is obtaining the highest value of CCT with the minimum SCES. Moreover, the constraint is the limit of SCES value and the power balance. The objective function and the constraint are explained in Eqs. (11) - (13), respectively.

$$
\text { Obj.function }(f)=\text { Minimize (SCES value })
$$

$$
\begin{gathered}
M_{i} \dot{\omega}_{i}=P_{m i}-P_{e i}(\delta)-P_{S C E S}-D_{i}\left(\delta_{i}\right) \\
P_{S C E S, \min } \leq P_{S C E S} \leq P_{S C E S, \max }
\end{gathered}
$$

where $P_{S C E S, \text { min }}$ and $P_{S C E S, \text { max }}$ are the minimum and the maximum range of SCES power.

For the first step, the SCES value will be randomized for the CCT calculation. CCT value is determined using the critical trajectory method. After that, the FA parameters, such as $\alpha, \beta$, and $\gamma$, are defined. $\alpha$ has an important role in controlling the random movements to get the solution. A small degree of accuracy for searching the optimal value 


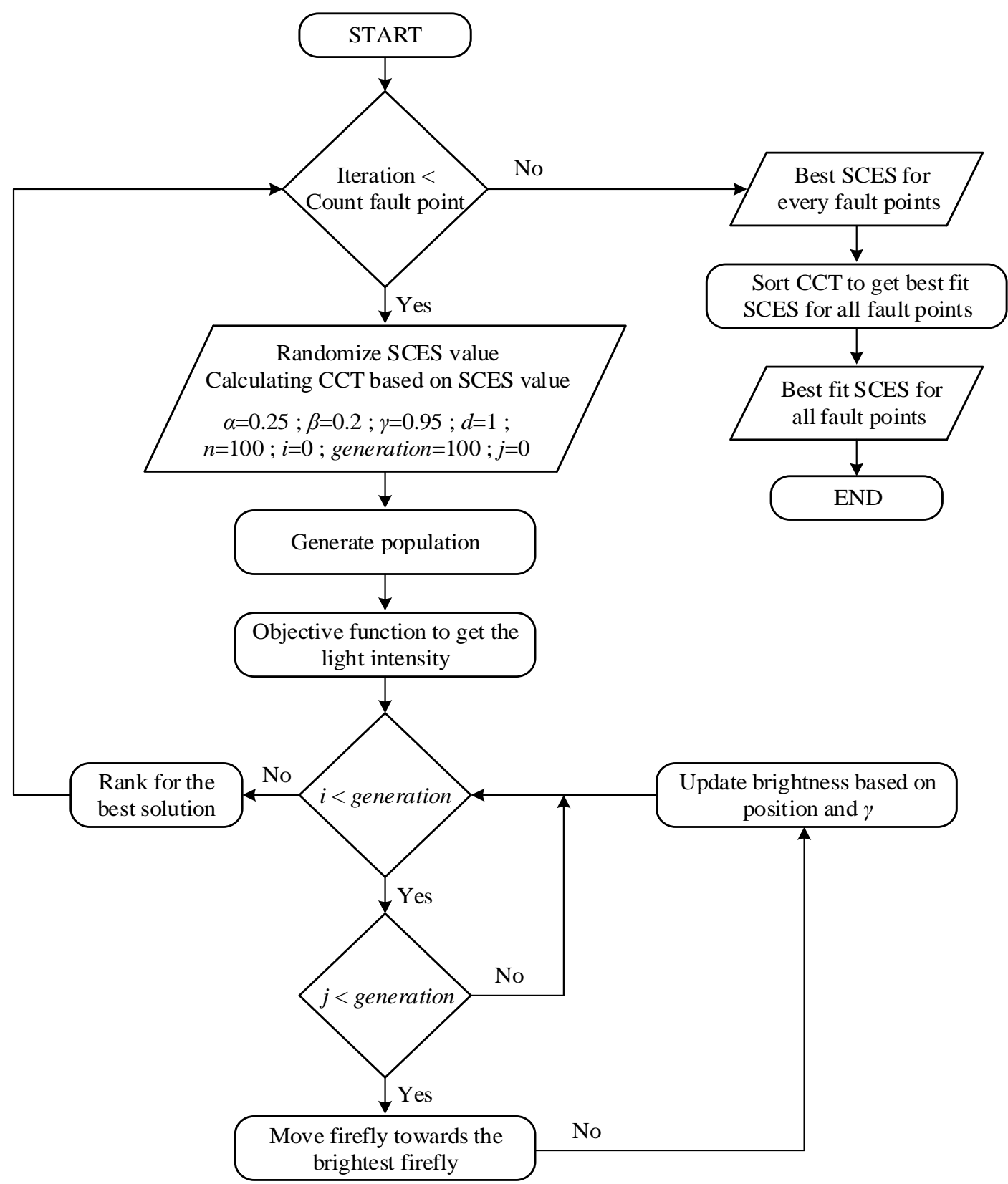

Figure. 2 Flowchart of the proposed method for finding the optimal SCES

will be obtained when using a high value of $\alpha$ because the random displacement becomes too wide. A small value of $\alpha$ is good for the convergence rate towards the desired point. However, $\alpha$ cannot be too small because it can eliminate the random displacement of a firefly. The value of $\beta \mathrm{s}$ determined by the attractiveness of the firefly, which is limited between 0 and 1. A higher value of $\beta$ will gives only a noncooperative random search.

Furthermore, $\gamma$ shown the variation of the attractiveness. $\gamma$ equal to zero means there is no variation or the attractiveness is constant; however, unlimited $\gamma$ means a completely random search with attractiveness equal to zero. Thus, after tuning the parameter, this paper use $\alpha, \beta$, and $\gamma$ are $0.25,0.2$, and 0.95 , respectively. Furthermore, generation $=100$ is chosen because it can give the satisfactory performance of the proposed method with minimum computation efforts. After that, the proposed method will calculate the optimal sizing of SCES with a higher value of CCT. Moreover, Fig. 2 shows a detailed flowchart of the proposed method in finding the sizing of SCES.

\section{Simulation result and discussion}

Simulation using a modified IEEE 3-machine 9bus system was performed to verify the proposed method. It is assumed that the system is double circuit line transmission, and the three-phase fault is subjected to the system. The critical trajectory method is used to obtain the value of CCT. Each 
value of CCT in the modified system will be compared with the base system, a standard system without SCES. Moreover, the FA will be used to get the optimal value of SCES, which has more stability index through the CCT value. The value of SCES is randomly from 0 until 1 in the per-unit base, with the precision 0.001, which is enough for the SCES sizing. Because each fault point has each optimal value of SCES according to the CCT value, the calculation of FA will be carried out in parallel at each fault point to shorten the computation time. After that, FA will give the final result of optimal SCES by comparing the optimal value at each fault point. Furthermore, Lagrange interpolation is used to show the effectiveness of the proposed method.

Table 1 shows the result comparison of CCT value for each fault location after adding the SCES, which is explained in Section 4. It can be concluded that the value of CCT is varies depending on the fault location. The closer the fault location with the generator (Fault A and Fault B), the smaller the CCT value. In fault location $A$, the CCT system is $0.41173 s$, which means the system remain stable until $0.41173 s$ before the protection system operates or the disturbance is cleared. However, the system becomes unstable when the disturbances still occur after $0.41173 s$.

Furthermore, Table 1 shows the comparison of the calculation time between the proposed method with modified Lagrange interpolation. It is seen that the proposed method way faster than the modified Lagrange interpolation. To illustrate the proposed method, the convergence characteristic for the CCT value at each point of fault with the generations as 100 is shown in Fig. 3. In the previous method, the sizing was done manually and only limited to one decimal point per-unit base $[25,26]$. However, the proposed method has better precision for the optimal SCES. Using FA, the result shows that the obtained SCES value varies depending on the fault location from $0.120-0.140$ p.u. Because of the constraint, which is mentioned in Section 4.3, SCES $=0.120$ p.u will be chosen.

To check the optimal value of SCES, which is obtained by the proposed method, Table 2 shows the validation of the CCT value. The CCT value from the proposed method will be compared with the base system without SCES. It can be concluded that the CCT value is increasing due to the installation of SCES in the system. For example, at fault point $C$, the CCT is increasing from $0.3272 \mathrm{~s}$ to $0.50045 \mathrm{~s}$. The deviation of the increment is $0.17325 \mathrm{~s}$ or around $52.94 \%$. The overall increase in CCT is $0.15766 \mathrm{~s}$ or around $54.61 \%$. Thus, it can be concluded that the proposed method proved its superiority compared
Table 1. Comparison of the optimal SCES at each fault point using FA

\begin{tabular}{|c|c|c|c|c|}
\hline \multirow{3}{*}{$\begin{array}{l}\text { Fault } \\
\text { point }\end{array}$} & \multirow{3}{*}{$\begin{array}{l}\text { SCES } \\
(p . u)\end{array}$} & \multirow{3}{*}{$\operatorname{CCT}(s)$} & \multirow{2}{*}{\multicolumn{2}{|c|}{ CPU (s) }} \\
\hline & & & & \\
\hline & & & FA & Lagrange \\
\hline A & 0.120 & 0.41173 & 93 & 1030 \\
\hline B & 0.121 & 0.40224 & 118 & 1280 \\
\hline $\mathrm{C}$ & 0.124 & 0.50045 & 86 & 960 \\
\hline $\mathrm{D}$ & 0.130 & 0.51945 & 84 & 940 \\
\hline $\mathrm{E}$ & 0.120 & 0.42902 & 88 & 980 \\
\hline $\mathrm{F}$ & 0.121 & 0.43644 & 103 & 1130 \\
\hline $\mathrm{G}$ & 0.120 & 0.43736 & 128 & 1380 \\
\hline $\mathrm{H}$ & 0.140 & 0.41635 & 106 & 1160 \\
\hline I & 0.140 & 0.75727 & 97 & 1070 \\
\hline
\end{tabular}

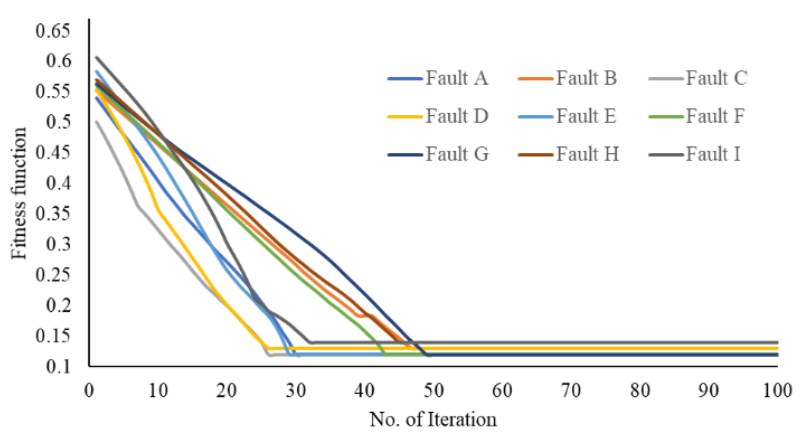

Figure. 3 Comparison of convergence characteristic for the CCT value at each fault point

Table 2. Comparison of the value of CCT with and without SCES 0.12 p. $u$

\begin{tabular}{|c|c|c|c|c|}
\hline \multirow{2}{*}{$\begin{array}{l}\text { Fault } \\
\text { point }\end{array}$} & \multicolumn{2}{|l|}{$\operatorname{CCT}(s)$} & \multicolumn{2}{|c|}{ CCT increment } \\
\hline & $\begin{array}{l}\text { Without } \\
\text { SCES }\end{array}$ & $\begin{array}{l}\text { With SCES } \\
=0.12 p . u\end{array}$ & $(s)$ & $(\%)$ \\
\hline $\mathrm{A}$ & 0.2288 & 0.41173 & 0.18293 & 79.95 \\
\hline B & 0.3121 & 0.40224 & 0.09014 & 28.88 \\
\hline $\mathrm{C}$ & 0.3272 & 0.50045 & 0.17325 & 52.94 \\
\hline D & 0.3247 & 0.51945 & 0.16763 & 51.62 \\
\hline$E$ & 0.2499 & 0.42902 & 0.17912 & 71.67 \\
\hline$F$ & 0.2440 & 0.43644 & 0.19244 & 78.86 \\
\hline G & 0.3178 & 0.43736 & 0.11956 & 37.62 \\
\hline $\mathrm{H}$ & 0.3148 & 0.41635 & 0.08804 & 27.96 \\
\hline I & 0.3641 & 0.75727 & 0.22583 & 62.02 \\
\hline
\end{tabular}

with the other existing method in terms of computation time and accuracy.

Moreover, Fig. 4 shows the effectiveness of the proposed method with the bases system. It shows the angular velocity, $\omega$, as the ordinate and the time in second as the abscissa for fault point at A. The base system is shown in the red line and the proposed system using a blue line. It is seen that using SCES in 


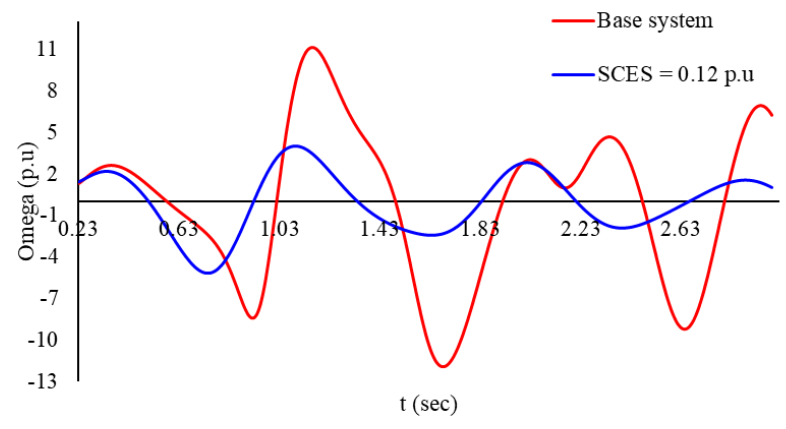

Figure. 4 Angular velocity $(\omega)$ and time $(s)$ curve of the generator for fault point at $\mathrm{A}$

the system, the $\omega$ can be damped when a fault happens. As a result, the CCT of the system can be increased.

\section{Conclusion and future works}

Nowadays, the power system is operated near its stability limit due to the imbalance between power demand and supply. Because of that, enhancing system stability becomes one of the main aspects in the power system. In this research work, FA is applied for resolving the optimal sizing of SCES with the objective function of extending CCT. As a result, system stability is enhanced, especially the transient stability.

The proposed method is validated on a modified IEEE 3-machine 9-bus system. At first, the calculation of CCT for the base system without SCES is done using the critical trajectory method. FA is carried out in parallel to obtain the optimal size of SCES at each fault point. As a result, it can shorten the computation time. After that, FA will give the final result of optimal SCES by comparing the optimal value at each fault point. By using the constraint, such as unbalance power and economic sector, the result shows that the optimal sizing of SCES is 0.120 p.u.

Furthermore, the result is compared with the base system to demonstrate the efficiency of the chosen SCES. The overall increase of CCT using 0.120 p.u as the chosen SCES is 0.15766 s or around $54.61 \%$. The obtained outcomes clearly indicate that the system with SCES is found can enhance transient stability. Moreover, the proposed method shows its superiority in computation time and accuracy compared with the existing method. The author believes that the proposed method is potentially implemented in a smart grid system in terms of transient stability enhancement. Further study is also necessary to take into account for bigger transmission system and also implement the other meta-heuristic algorithms.

\section{Conflicts of Interest}

The authors identify and declare that there is no any personal circumstances or interest that may be perceived as inappropriately influencing the representation or interpretation of reported research results.

\section{Author Contributions}

Conceptualization, Mauridhi Hery Purnomo, Ardyono Priyadi, and Vita Lystianingrum, Talitha Puspita Sari; methodology, Talitha Puspita Sari, Maya Prananda Sari, and Gabriela Evania Sulistyo; software, Talitha Puspita Sari, Maya Prananda Sari, and Gabriela Evania Sulistyo; validation, Talitha Puspita Sari; formal analysis, Talitha Puspita Sari, Mauridhi Hery Purnomo, Ardyono Priyadi, and Vita Lystianingrum; writing - original draft preparation, Talitha Puspita Sari; writing - review and editing, Mauridhi Hery Purnomo, Ardyono Priyadi, and Vita Lystianingrum, Talitha Puspita Sari; visualization, Talitha Puspita Sari, Maya Prananda Sari, and Gabriela Evania Sulistyo; supervision, Mauridhi Hery Purnomo, Ardyono Priyadi, and Vita Lystianingrum; project administration, Talitha Puspita Sari.

\section{Acknowledgments}

The author would like to thank Kementerian Riset, Teknologi dan Pendidikan Tinggi Republik Indonesia (Kemenristekdikti RI) and Institut Teknologi Sepuluh Nopember Indonesia (ITS) for providing facilities and support this work through PMDSU scholarship scheme.

\section{References}

[1] D. Gielen, F. Boshell, D. Saygin, M. D. Bazilian, N. Wagner, and R. Gorini, "The role of renewable energy in the global energy transformation", Energy Strategy Reviews, Vol. 24, pp. 38-50, 2019.

[2] O. A. Alimi, K. Ouahada, and A. M. AbuMahfouz, "A Review of Machine Learning Approaches to Power System Security and Stability", IEEE Access, Vol. 8, pp. 113512113531, 2020.

[3] O. A. Zongo and A. Oonsivilai, "Optimal placement of distributed generator for power loss minimization and voltage stability improvement", Energy Procedia, Vol. 138, pp. 134-139, 2017.

[4] U. Sultana, A. B. Khairuddin, M. M. Aman, A. S. Mokhtar, and N. Zareen, "A review of optimum DG placement based on minimization 
of power losses and voltage stability enhancement of distribution system", Renewable and Sustainable Energy Reviews, Vol. 63, pp. 363-378, 2016.

[5] R. C. Dugan, S. Santoso, M. F. McGranaghan, and H. W. Beaty, Electrical Power Systems Quality, McGraw Hill Professional, 2002.

[6] T. P. Sari, A. Priyadi, M. Pujiantara, and M. H. Purnomo, "Enhancing the coordination of reverse power, overcurrent, under-frequency, and under-voltage relays using transient stability analysis in real plant applications", Ain Shams Engineering Journal, Vol. 11, No. 1, pp. 1-9, 2020.

[7] T. A. Jumani, M. W. Mustafa, A. S. Alghamdi, M. Md. Rasid, A. Alamgir, and A. B. Awan, "Swarm Intelligence-Based Optimization Techniques for Dynamic Response and Power Quality Enhancement of AC Microgrids: A Comprehensive Review", IEEE Access, Vol. 8, pp. 75986-76001, 2020.

[8] B. J. Rani and A. S. Reddy, "Optimal Allocation and Sizing of Multiple DG in Radial Distribution System Using Binary Particle Swarm Optimization", International Journal of Intelligent Engineering and Systems, Vol. 12, No. 1, pp. 290-299, 2019.

[9] D. Ramakrishnan and S. Pushparajan, "Unified Particle Swarm Optimization Based Distributed Generation Placement in Radial Power Systems", International Journal of Intelligent Engineering and Systems, Vol. 11, No. 1, pp. 104-112, 2018.

[10] S. Ibrahim, S. Alwash, and A. Aldhahab, "Optimal Network Reconfiguration and DG Integration in Power Distribution Systems Using Enhanced Water Cycle Algorithm", International Journal of Intelligent Engineering and Systems, Vol. 13, No. 1, pp. 379-389, 2020.

[11] D. Nataraj, R. Loganathan, M. Veerasamy, and V. Jawalkar, "Optimizing Radial Distribution System for Minimizing Loss Reduction and Voltage Deviation Indices Using Modified Grey Wolf's Algorithm", International Journal of Intelligent Engineering and Systems, Vol. 11, No. 6, pp. 177-189, 2018.

[12] X.-S. Yang, "Firefly algorithms for multimodal optimization", Stochastic Algorithms: Foundations and Applications, SAGA 2009, Lecture Notes in Computer Sciences, Vol. 5792, pp. 169-178, 2009.

[13] X.-S. Yang, "Firefly Algorithm, Stochastic Test Functionsand Design Optimisation", Int. Journal Bio-Inspired Computation, Vol. 2, No. 2, pp.78-84, 2010.
[14] P. Balachennaiah, M. Suryakalavathi, and P. Nagendra, "Optimizing real power loss and voltage stability limit of a large transmission network using firefly algorithm", Engineering Science and Technology, an International Journal, Vol. 19, No. 2, pp. 800-810, 2016.

[15] K. Jagatheesan, B. Anand, S. Samanta, N. Dey, A. S. Ashour, and V. E. Balas, "Design of a proportional-integral-derivative controller for an automatic generation control of multi-area power thermal systems using firefly algorithm", IEEE/CAA Journal of Automatica Sinica, Vol. 6, No. 2, pp. 503-515, 2019.

[16] S. S. Gokhale and V. S. Kale, "An application of a tent map initiated Chaotic Firefly algorithm for optimal overcurrent relay coordination", International Journal of Electrical Power \& Energy Systems, Vol. 78, pp. 336-342, 2016.

[17] M. P. Sari, G. E. Sulisityo, M. Pujiantara, and M. H. Purnomo, "Chaotic Firefly with Tent Map Algorithm for Overcurrent Relay in Meshed Distribution System", In: Proc. of International Conf. on Information Technology and Electrical Engineering (ICITEE), Bali, Indonesia, pp. 1-6, 2018.

[18] A. Tjahjono, D. O. Anggriawan, A. K. Faizin, A. Priyadi, M. Pujiantara, T. Taufik, and M. H. Purnomo, "Adaptive modified firefly algorithm for optimal coordination of overcurrent relays", Transmission Distribution IET Generation, Vol. 11, No. 10, pp. 2575-2585, 2017.

[19] A. Ameli, M. Farrokhifard, A. Ahmadifar, A. Safari, and H. A. Shayanfar, "Optimal tuning of Power System Stabilizers in a multi-machine system using firefly algorithm", In: Proc. of International Conf. on Environment and Electrical Engineering, Wroclaw, Poland, pp. 461-466, 2013.

[20] M. Singh, R. N. Patel, and D. D. Neema, "Robust tuning of excitation controller for stability enhancement using multi-objective metaheuristic Firefly algorithm", Swarm and Evolutionary Computation, Vol. 44, pp. 136147, 2019.

[21] S. Ranganathan, M. Surya Kalavathi, and C. Asir Rajan C., "Self-adaptive firefly algorithm based multi-objectives for multi-type FACTS placement", Transmission Distribution IET Generation, Vol. 10, No. 11, pp. 2576-2584, 2016.

[22] P. C. Pradhan, R. K. Sahu, and S. Panda, "Firefly algorithm optimized fuzzy PID controller for AGC of multi-area multi-source power systems with UPFC and SMES", Engineering Science 
and Technology, an International Journal, Vol. 19, No. 1, pp. 338-354, 2016.

[23] Y. Liu, Y. Tang, Y. Xu, J. Shi, X. Shi, Z. Wang, J. Deng, L. Ren, and S. Yan, "Status Evaluation Method for SMES Used in Power Grid", IEEE Transactions on Applied Superconductivity, Vol. 25, No. 5, pp. 1-10, 2015.

[24] Y. Tang, C. Mu, and H. He, "SMES-Based Damping Controller Design Using FuzzyGrHDP Considering Transmission Delay", IEEE Transactions on Applied Superconductivity, Vol. 26, No. 7, pp. 1-6, 2016.

[25] T. P. Sari, A. Priyadi, M. Pujiantara, N. Yorino, and M. H. Purnomo, "Improving Transient Stability Assessment by Installing Super Capacitor Energy Storage using Critical Trajectory Method based on Modified Losing Synchronism", In: Proc. of International Seminar on Intelligent Technology and Its Applications (ISITIA), Bali, Indonesia pp. 51-55, 2018.

[26] A. Priyadi, T. P. Sari, I. Hafidz, M. Pujiantara, N. Yorino, and M. H. Purnomo, "Losing Synchronism Technique based on Critical Trajectory Method for Obtaining the CCT with Installing SCES", In: Proc. of International Seminar on Intelligent Technology and Its Applications (ISITIA), Bali, Indonesia, pp. 6366, 2018.

[27] P. S. Talitha, I. Hafiz, R. M. Vincentius, P. Ardyono, L. B. P. Vita, and H. P. Mauridhi, "Optimizing the Generator Critical Clearing Time using Super Capacitor Energy Storage in the Grid Power System with Differential Evolution Algorithm", In: Proc. of International Symposium on Diagnostics for Electrical Machines, Power Electronics and Drives (SDEMPED), Toulouse, France pp. 147-152, 2019.

[28] D. O. Akinyele and R. K. Rayudu, "Review of energy storage technologies for sustainable power networks", Sustainable Energy Technologies and Assessments, Vol. 8, pp. 7491, 2014.

[29] Y. Cho and H. A. Gabbar, "Review of energy storage technologies in harsh environment", Saf. Extreme Environ., Vol. 1, No. 1, pp. 11-25, 2019.

[30] P. Kundur, J. Paserba, V. Ajjarapu, G. Anderson, A. Bose, C. Canizares, N. Hatziargyriou, D. Hill, A. Stankovic, C. Taylor, T. V. Cutsem, and V. Vittal, "Definition and classification of power system stability IEEE/CIGRE joint task force on stability terms and definitions", IEEE
Transactions on Power Systems, Vol. 19, No. 3, pp. 1387-1401, 2004.

[31] P. M. Anderson and A. A. Fouad, Power System Control and Stability, IEEE Press, New York, 1994.

[32] G. T. Heydt, Computer Analysis Methods for Power Systems, Macmillan Publishing Company, New York, 1986.

[33] H.-D. Chiang, Direct Methods for Stability Analysis of Electric Power Systems: Theoretical Foundation, BCU Methodologies, and Applications. Hoboken, NJ, USA: John Wiley \& Sons, Inc. 2010.

[34] N. Yorino, A. Priyadi, H. Kakui, and M. Takeshita, "A New Method for Obtaining Critical Clearing Time for Transient Stability", IEEE Transactions on Power Systems, Vol. 25, No. 3, pp. 1620-1626, 2010.

[35] A. Priyadi, N. Yorino, Y. Sasaki, M. Tanaka, T. Fujiwara, Y. Zoka, H. Kakui, and M. Takeshita, "Comparison of Critical Trajectory Methods for Direct CCT Computation for Transient Stability", IEEJ Trans. on Power and Energy, Vol. 130, No. 10, pp. 870-876, 2010.

[36] J. J. Q. Yu, A. Y. S. Lam, D. J. Hill, and V. O. K. Li, "Delay Aware Intelligent Transient Stability Assessment System", IEEE Access, Vol. 5, pp. 17230-17239, 2017.

[37] X.-S. Yang, Nature-inspired Metaheuristic Algorithms, Luniver Press, UK, 2008. 